Caligrama, Belo Horizonte, v. 22, n. 1, p. 51-70, 2017

\title{
Esopo em Portugal: das origens à contemporaneidade
}

\section{Aesop in Portugal: from origins to contemporaneity}

\author{
Mafalda Frade ${ }^{1}$ \\ Universidade Nova de Lisboa, Lisboa / Portugal \\ Universidade de Aveiro, Aveiro / Portugal \\ mmfrade.ua@gmail.com
}

Resumo: Esta investigação pretende compreender como se processou a recepção de Esopo na Literatura Portuguesa, da Idade Média à contemporaneidade, analisando a relação entre o gênero fabulístico e a literatura infantojuvenil e para adultos. Partindo de um corpus de fábulas esopianas e, dentro dele, de uma fábula específica, este trabalho analisará as características que permitirão demonstrar a alteração, ao longo do tempo, do tipo de público-alvo e do objetivo edificante das obras em estudo. Observarse-á, assim, que a fábula, em Portugal, passou de um gênero de literatura para adultos para um típico da literatura infantojuvenil, registando-se, atualmente, alguma tendência para o regresso às origens a este nível.

Palavras-chave: Esopo; fábula; literatura portuguesa.

Abstract: This research aims to understand how Aesop's reception in Portuguese Literature from the Middle Ages to contemporaneity was made, analysing the relationship between the fable and literature for adults and for children/youth. In this context, starting from a corpus of fables and looking to a specific Aesop fable, we will analyse characteristics that will help to demonstrate how the target audience and the moralizing purpose of the fables changed over time. It will thus be observed that the fable, in Portugal, has gone from a genre of adult literature to a typical genre of

\footnotetext{
${ }^{1}$ Financiamento da Fundação para a Ciência e Tecnologia, Portugal (SFRH/BPD/47528/2008).
} 
the literature for childhood and youth, and there is now some tendency to return to the origins at this level.

Keywords: Aesop; fable; portuguese literature.

Recebido em: 31 de março de 2017.

Aprovado em: 15 de julho de 2017.

\section{Introdução}

A primeira obra portuguesa sobre Esopo remonta a uma tradução medieval. E nos séculos seguintes, à exceção do século XVI, editaramse coletâneas exclusivamente de Esopo, outras que o têm por base e fábulas esopianas isoladas. Essas obras não tiveram sempre o mesmo destinatário: muitas destinam-se a públicos específicos - a adultos, ao público infantojuvenil -, seja porque tal é explicitamente referido numa ou outra obra, seja porque há características que o indiciam (como as ilustrações, cujo traço é normalmente infantil).

Nesse âmbito, pretende-se estudar aspetos da recepção de Esopo em Portugal, da Idade Média à contemporaneidade. Para isso, a partir de características das obras do corpus investigado (como os paratextos) e da análise do epimítio de uma fábula, procuraremos identificar se o público-alvo dos autores/tradutores se confirma, de acordo com as características evidenciadas, e qual objetivo eles teriam em mente, no sentido de entrever se houve variações ao longo dos séculos.

Em termos metodológicos, o corpus foi primeiramente constituído por coletâneas de fábulas de Esopo, desde a primeira conhecida em Portugal até as mais atuais:

- Livro de Exopo, Anónimo (séculos XIV-XV);

- Vida e fábulas do insigne fabulador Grego Esopo, Vidigueira, 1643;

- Fabulas de Esopo reduzidas a rima, Guerreiro, 1788;

- 113 Fabulas de Esopo, Pereira, 1890;

- Fábulas de Esopo, Frederico, 1930; 
- Fábulas de animais, Machado, 1957;

- As cem mais famosas fábulas de Esopo, Bragança, 1984;

- As mais belas fábulas de Esopo (tradução: Carlos Jesus), 1994;

- Fábulas de Esopo, Kincaid (tradução de Álvaro Fernandes), 1997;

- Fábulas de Esopo, Mota, 2004;

- Fabuloso Esopo, Parreira, 2005;

- Fábulas de Esopo para executivos, Rangel, 2008;

- As fábulas de Esopo, Waters, 2011.

Nesses fabulários procurou-se encontrar um denominador comum - uma fábula - para avaliar a conveniência de integrar mais obras no corpus, tendo sido possível encontrar apenas uma - "O Leão e o Rato" -, razão que nos levou a estudá-la. Essa fábula só não surge na obra de Pereira (integra-a na sua coletânea de Fedro) ${ }^{2}$, pelo que, para o século XIX, optámos por integrar no corpus outras obras onde ela aparece:

- Fabulas de Phedro, Pereira, 1871;

- Fabulário, O’Neill, 1885;

A esse conjunto juntaram-se ainda obras dos séculos XX e XXI que, não sendo totalmente dedicadas a Esopo, englobam a fábula em estudo e possuem especificidades interessantes:

- Cinquenta fabulas de Fedro, Tavares, 1929;

- Fábulas para aprender, Sarabando, 2015;

- O leão e o ratinho, Mantegazza, 1997;

- O leão e o rato/Capuchinho vermelho, Fonseca, 2000;

- O rato e o leão, Oom, 2005a;

- O leão e o rato, Oom/Semedo, 2005 b.

\section{A fábula: considerações teóricas}

\footnotetext{
${ }^{2}$ Fedro foi um escravo romano que, para além das suas criações, passou à escrita fábulas ditas "de Esopo" (RODRÍGUEZ ADRADOS, 1979, p. 134-140), mítico narrador de fábulas a quem é atribuído um número vasto de relatos que são, na realidade, de outros autores. A partir do século V a.C., o nome de Esopo foi muito utilizado para identificar fábulas, sendo a expressão "lógoi esópicos" usada desde Aristófanes para indicar este género por oposição a outros (RODRÍGUEZ ADRADOS, 2005, p. 25; 43; RODRÍGUEZ ADRADOS, 1979, p. 28-31; 286-298; KURKE, 2011, p. 13-14). Assim, não é invulgar encontrarmos o nome de Esopo em diferentes fabulários, incluindo de Fedro.
} 


\subsection{Características primordiais}

As origens da literatura para a infância radicam na literatura oral, que descende de "mitos, crenças e rituais religiosos, [...] narrativas, canções, adivinhas" (SILVA, 1981, p. 11) ensinados oralmente às crianças, de geração em geração. A fábula não é exceção, pertencendo ao domínio da literatura tradicional, porque descendente de um "folclore primitivo" (RAMOS, 2005, p. 170), tal como aconteceu com os contos populares.

Os primeiros sinais da existência da fábula encontram-se na Mesopotâmia (3000 a.C.), mas ela desenvolveu-se exponencialmente na Grécia Antiga a partir do séc. VIII a.C. Na sua origem, surgia frequentemente sob a forma poética e destinava-se ao público adulto presente em festas populares, celebrações rituais ou banquetes em que a sátira e a crítica estavam presentes, sendo usada para veicular a sabedoria popular. ${ }^{3}$ Contudo, foi também cultivada por escritores como Hesíodo, Arquíloco, Semónides, Aristófanes ou Sócrates, não se limitando, assim, às camadas mais baixas da população. ${ }^{4}$ Sendo um género da literatura sapiencial de objetivo edificante, não é estranho, assim, que a fábula, pelo seu tamanho, simplicidade e propósito, tenha sido adotada desde o século V a.C. como ferramenta pedagógica, atingindo o público infantil. ${ }^{5}$ Platão, por exemplo, é um dos que manifesta preocupações a esse respeito:

Faremos uma seleção de fábulas, aprovando as boas ou belas e rejeitando as que não são. Convenceremos, em seguida, as amas e mães a contar às suas crianças as fábulas que selecionamos, uma vez que elas moldarão as almas de suas crianças por meio de histórias. (PLATÃO, 2012. p. 105)

Da Grécia, chega depois a Roma por mão de fabulistas como Fedro ou Aviano, mantendo-se também aqui como instrumento pedagógico. ${ }^{6}$

\footnotetext{
${ }^{3}$ Cf. RODRÍGUEZ ADRADOS, 2005, p. 30; 57-58; RODRÍGUEZ ADRADOS, 1979, p. 255-261; KURKE, 2011, p. 3-4.

${ }^{4}$ Cf. RODRÍGUEZ ADRADOS, 2005, p. 21-28; 41; 56; RODRÍGUEZ ADRADOS, 1979, p. 307-319; KURKE, 2011, p. 47; 156; ROTHWELL, 1995, p. 233.

${ }^{5}$ Cf. PEREIRA, 1987, p. 360; FERREIRA, 2006, p. 22-27; MARROU, 1948, p. 231; 258-259; RODRÍGUEZ ADRADOS, 2005, p. 34-39; 59; FERREIRA, 2014, p. 45; 52-54; 60-63.

6 Cf. RODRÍGUEZ ADRADOS, 2005, p. 22; 42; LERER, 2009, p. 28.
} 
Embora seja um género bastante antigo, a fábula é particularmente constante, na medida em que manteve as suas características básicas da Antiguidade aos nossos dias. Objeto de inúmeras definições, apesar da dificuldade em se delimitar as suas características (por partilhar algumas com outros géneros) $)^{7}$, a fábula é, por consenso, uma narrativa fictícia breve (em prosa ou verso) e relativamente simples de uma situação típica da realidade humana, que pode repetir-se constantemente, e que utiliza sobretudo animais, plantas ou objetos, mas também, figuras humanas ${ }^{8}$ como personagens alegóricas que simbolizam comportamentos e realidades humanas. Nessa medida, possui uma dimensão pragmática: apresenta uma concepção crítica e realista da vida e da sociedade e conduz a conclusões de ordem ético-moral (sob a forma de crítica, advertência ou ensinamento, por vezes até políticos ${ }^{9}$ que buscam a mudança de comportamento do leitor/ouvinte. Essa conclusão moral, que constitui a sua característica diferenciadora em relação ao conto, por exemplo ${ }^{10}$, geralmente surge no epimítio, mas pode ser inferida, pois a presença de uma frase moralizadora não é uma característica obrigatória do género. ${ }^{11}$

\subsection{A fábula e a literatura para a infância em Portugal}

Só a partir do século XIX, grosso modo, passou a existir, em Portugal, uma literatura para a infância. Até então, culturalmente, não existia no país uma visão específica da criança, que era olhada como um adulto em miniatura. Essa situação radica na evolução histórico-cultural da nação: após a queda do Império Romano, em que houve tentativas de estender o ensino à população comum, ${ }^{12}$ dadas a distinta cultura dos invasores e a fuga da classe culta das províncias romanas conquistadas,

\footnotetext{
${ }^{7}$ Cf. REIS; LOPES, 1994, p. 158-159; SCHON; BERKIN, 1996, p. 61-62; BARRETO, 2002, p. 187; PORTELLA, 1983, p. 124; TARRÍO VARELA et al., 1998, p. 359; RODRÍGUEZ ADRADOS, 2005, p. 24; 42; 56-63; RODRÍGUEZ ADRADOS, 1979, p. $18 ; 36-52$.

${ }^{8}$ Desde os primórdios, a fábula incluiu como personagens homens ou deuses, ainda que tal não fosse muito frequente (RODRÍGUEZ ADRADOS, 2005, p. 24; 33; 43).

${ }^{9}$ Cf. KURKE, 2011, p. 133-134; FERREIRA, 2014, p. 60.

${ }^{10}$ Cf. PORTELLA, 1983, p. 123; PEREIRA, 2003, p. 21.

${ }^{11}$ Cf. DEZOTTI, 2003, p. 22-23; FERREIRA, 2014, p. 56-60.

12 "Au IV siècle [...] il n'y a pas de ville de quelque importance qui n'ait une école municipale." (PAUL, 1973, p. 52).
} 
na Europa o nível cultural da população baixou drasticamente entre os séculos V e VIII d.C. O acesso à cultura, mesmo nas cortes reais, tornouse reduzido, concentrando-se sobretudo no clero, cuja influência sobre a população aumentara. ${ }^{13}$ Num mundo pouco culto, algumas crianças das classes mais altas tinham acesso à cultura e eram minimamente escolarizadas, sobretudo por padres, mas a maioria não recebia qualquer educação formal. Contudo, as poucas que tinham acesso ao ensino continuaram a contactar com a fábula, entre outros géneros:

The church absorbed the old traditions of the Roman schoolroom, adapting instruction in grammatica to the precepts of Catholic doctrine. [...] The Aesopica was always there, but now new genres entered into school and home. (LERER, 2009, p. 57)

Apesar disso, os anos de infância, propriamente ditos, eram poucos: quando autónomas, as crianças eram integradas na sociedade adulta, tornando-se produtivas. Assim, e apesar da criança não ser socialmente invisível, não lhe era dada importância como grupo nem havia razão para tal, pela ínfima escolarização, para "investir" na literatura infantil.

Essa situação só muda a partir dos séculos XVI-XVII (já depois do reflorescimento cultural em Portugal, sobretudo a partir do século XIV, com a "Ínclita Geração"), época em que começam a surgir livros com intenções pedagógicas para crianças, como os de João de Barros. Contudo, só no século XIX aumenta significativamente a produção para crianças: variados autores - como Guerra Junqueiro, João de Deus, Adolfo Coelho e Maria Amália Vaz de Carvalho -, preocupados com a formação do caráter ${ }^{14}$ e tendo por missão dar às crianças uma literatura mais adequada, publicam obras destinadas à infância, ainda que bastante eruditas (tornando-as de difícil entendimento) e quase sem ilustrações ${ }^{15}$.

\footnotetext{
${ }^{13}$ Cf. BLOCH, 1982, p. 55102; PAUL, 1973, p. 90-91.

${ }^{14}$ Essa situação é compreensível se contextualizarmos a cultura naquele momento: no século XVII, Cervantes considerava que uma boa biblioteca teria 60 volumes e, até ao século XIX, as crianças eram entregues a criados analfabetos durante os primeiros anos de vida (LEMOS, 1972, p. 9), sendo integradas no mundo dos adultos quando atingiam a idade escolar. Assim, a leitura não tinha em conta as especificidades das crianças, mas era um instrumento que procurava levá-las a assumir o comportamento do adulto, motivo pelo qual ela era composta por obras de formação.

${ }^{15}$ Cf. ROCHA, 2001, p. 22-27; 37-39; ROSADO, 2011, p. 23; PATRIARCA, 2012, p. 1; LEMOS, 1972, p. 7-19.
} 
Para isso, optam por géneros cuja estrutura e temática se aproximava dos gostos infantis: literatura de exemplaridade (biografias de santos ou heróis), contos tradicionais ou fabulários dos quais as crianças retiravam uma moralidade prática. Com o avançar do século $\mathrm{XX}$, e apesar dos constrangimentos que as guerras mundiais e a situação política trouxeram ao desenvolvimento da literatura portuguesa para a infância, a linguagem foi-se adequando cada vez mais ao público infantil e o mercado foi crescendo, existindo, hoje em dia, um mercado editorial robusto em Portugal relacionado com a infância.

Ao longo desse período de desenvolvimento da literatura para a infância em Portugal, a fábula foi permanecendo e conquistando um lugar próprio. Assim, e ainda que sejam "'obras anexadas' à literatura para a infância, não escritas para este público, mas inúmeras vezes adaptadas" (GOMES, 2007, p. 6) ${ }^{16}$, as fábulas passaram, na atualidade, a estar associadas predominantemente à infância, revelando-se, ainda hoje, bastante profícua a relação entre o público infantil e esse género literário.

\section{Esopo em Portugal}

Dos inúmeros fabulários e edições avulsas de fábulas de Esopo, destacam-se alguns mais representativos, pelas características textuais e paratextuais que revelam. Importa, contudo, perceber se foram desde sempre destinados ao público infantil e revelam a mesma intencionalidade, ou se há variações relevantes a registar.

O primeiro fabulário de Esopo em Português de que há registo é medieval. Trata-se do Livro de Exopo, tradução anónima do grego para vernáculo do século XIV ou XV. É no paratexto que temos acesso à intencionalidade do tradutor que, depois de breve excurso sobre a vida de Esopo, revela a intenção deste: escreve para ensinar aos homens como "devem de viver virtuosamente e guardar sse dos males" (LIVRO..., 1994, fol. $1 \mathrm{r}-\mathrm{v}$ ). Torna-se assim percetível que o livro se destina a adultos, mais concretamente a todos os que buscam uma vida virtuosa e de bem. Depois, compara o livro à casca dura da noz e o seu interior ao miolo saboroso, referindo que "assy este livro tem em ssy escondido muytas notavees semtenças” (LIVRO..., 1994, fol. 1 r-v).

${ }^{16}$ Cf. também PEREIRA, 2003, p. 15. 
Depois dessa tradução, só no século XVII surge novo fabulário esopiano (VIDIGUEIRA, 1643), que conheceu catorze edições e reimpressões (MORAIS, [2008?], p. 6). Na edição de 1643, a que acedemos, $\mathrm{o}$ autor advoga o valor das fábulas, considerando-as pérolas douradas que permitiam aos mais rudes compreender a doutrina ensinada, demonstrando que também esse fabulário se destina a adultos:

Aristoteles affirma (\& delle o tras Sancto Thomas) que as fabulas se inventarão pera os homens fugirem dos viços $\&$ seguirem a virtude. [...] Estando logo esta verdade tam fundada, quis eu seguilla \& seguir o concelho a que Horacio dá a palma, a saber, Mistura o doce cõ o proveitoso, o doce sam as fabulas, o proveitoso sua significaçoens. (VIDEIRA, 1643, Prólogo, f. A2v).

O mesmo sucede no século seguinte: Guerreiro (que tem a particularidade de seguir a tradição antiga e utilizar o modo poético) identifica taxativamente o seu público-alvo: "escrevo para instruir o povo [...] O meu principal intento foi fazer estas Fabulas agradaveis aos Leitores, para excitar neles a curiosidade de as lerem, e se aproveitarem da doutrina, que ellas contêm" (GURREIRO, 1788, p. 7; 9).

A essa obra seguem-se, no século XIX, edições de Pereira em que encontramos fábulas de Esopo. A primeira, Fabulas de Phedro, tem o intuito de ser usada, como é explicitado no frontispício, "para auxílio dos estudantes de latim" (PEREIRA, 1871, frontspício), ao passo que, na segunda (PEREIRA, 1890), nada é dito sobre o público-alvo, embora uma referência às traduções realizadas permita pensar que o autor teria em mente os mesmos destinatários do fabulário de Fedro.

Ao invés de Pereira, a coletânea poética de O'Neill é explícita no seu público-alvo: "livro destinado à educação dos filhos do Povo Portuguez” (O’NEILL, 1885, dedicatória, p. XIII). Reveste-se, assim, de especial interesse para a literatura infantojuvenil, por ser o primeiro fabulário infantil em português, marcando o período em que a fábula passa a usar-se para recreio e ensinamento das crianças no país.

Essa tendência é mais pronunciada no século XX, época em que Esopo começa a surgir frequentemente na literatura infantil e despontam preocupações estéticas: depois da obra de Tavares - que revela, no prefácio, destinar-se a crianças e conter planos de estudo para auxiliar os professores -, com Frederico surge a primeira edição conhecida cuja capa afirma explicitamente tratar-se de uma obra infantil (pertence à coleção "Contos para crianças") e possui menção à ilustradora. 
Em 1957, Machado também manifesta preocupações estéticas (a obra é ilustrada) e revela não ter em mente uma faixa etária específica ao declarar que a fábula "é uma fórmula que serve e agrada a todas as idades e em todas as épocas" (MACHADO, 1957, p. 10).

A tendência para a inclusão de ilustrações é apurada com o avançar do século, tornando-se a fábula muito usada na literatura para a infância. De facto, e excetuando a obra de Bragança, que parece destinar-se a adultos ${ }^{17}$, os restantes fabulários esopianos do século XX são marcadamente para um público infantojuvenil, não apenas pela linguagem utilizada, mas também por serem ilustrados, havendo até tendência para incluir na capa o nome do ilustrador em detrimento do autor/tradutor (veja-se o fabulário de $1994^{18}$ e KINCAID, 1997). A essas obras acrescenta-se ainda a fábula avulsa $O$ leão $e$ o ratinho (MANTEGAZZA, 1997), claramente destinada a crianças, dados não apenas a ilustração e a linguagem, mas também o facto de ser um livro cartonado e com orifícios, tendo ainda a particularidade de se tratar de texto poético.

O início do século XXI trouxe à luz em Portugal pelo menos oito edições relacionadas com Esopo ${ }^{19}$, quase todas ilustradas, demonstrando a vitalidade atual da fábula na literatura infantojuvenil.

A de Mota está mais direcionada para o público juvenil, dadas a linguagem, a dimensão da fonte e as ilustrações por vezes disfóricas - corvo de asas cortadas (MOTA, 2004, p. 7) ou águia atravessada por seta (MOTA, 2004, p. 30), por exemplo.

Outras duas - Parreira (2005) e Waters (2011) - destinam-se ao público infantojuvenil, apresentando, a primeira, a particularidade de o índice ser construído como um caminho que se percorre (como o jogo infantil de ligar pontos para fazer uma imagem).

Já outro fabulário, adaptado para o português por Sarabando, ${ }^{20}$ chama a atenção pelos paratextos. Sendo, pelo tipo de ilustração (e como o prefácio indica), uma obra para a infância, revela uma tentativa

\footnotetext{
${ }^{17}$ Não possuindo desenhos nem explicitando o público-alvo, o formato - livro de bolso -, a dimensão reduzida da fonte e a ausência de ilustrações apontam para um público adulto.

${ }^{18} \mathrm{O}$ nome do tradutor aparece num tipo diminuto na ficha técnica (guardas finais).

${ }^{19}$ Há mais fabulários (de La Fontaine, Fedro etc.) e inúmeras edições avulsas de fábulas.

${ }^{20}$ A ficha técnica refere à origem espanhola da primeira edição, mas não ao nome do autor, destacando apenas o ilustrador e a tradutora.
} 
clara de atingir o público-alvo por intermédio dos adultos educadores: o prefácio é dedicado às vantagens da leitura em família e o posfácio inclui um índice remissivo dos valores a explorar com as crianças e sugestões para fomento do gosto pela leitura.

Há ainda três edições avulsas voltadas para um público infantil: Fonseca (2000) e Oom (2005a, 2005b). A primeira não faz referência ao autor da edição original (só a tradutora). Já a segunda engloba, no fim, dois jogos para crianças; e a terceira inclui um CD-ROM com música inédita e/ou narração oral da fábula e a tradução da fábula poética de La Fontaine, da autoria de Semedo (séc. XIX), que está na origem do livro.

Por fim, destacamos uma oitava obra, de Rangel (2008), que é, no século XXI, a única destinada a um público adulto, como o título e a badana explicitam. Essa obra não tem ilustrações, é brochada e apresenta um índice remissivo de valores empresariais (como qualificação, competência, respeito).

Com isso, podemos observar que, sob o ponto de vista do público-alvo, a fábula, em Portugal, segue o caminho histórico da literatura para a infância no que diz respeito à literatura de tradição oral: inicialmente voltada para adultos, com o tempo, atinge o domínio da literatura infantojuvenil. Contudo, já no século XXI, o fabulário de Rangel, destinado a um público-alvo adulto e exigente, conduz-nos aos primórdios do género. Assim se verifica que há espaço para que a fábula, contemporaneamente associada à infância, possa voltar a ser apreciada por adultos, numa espécie de fenómeno crossover, ${ }^{21}$ o que nos permite verificar que tem suficiente maleabilidade para se adaptar a qualquer público em qualquer tempo.

\section{4 "O leão e o rato": uma fábula esopiana, várias intencionalidades}

Analisadas brevemente características do corpus escolhido, é altura de investigar uma fábula presente em todas as obras, procurando descobrir se se respeitam as características basilares do género, se o texto

\footnotetext{
${ }^{21}$ A literatura crossover refere-se a "fiction that crosses from child to adult or adult to child audiences” (BECKETT, 2009, p. 4), ou seja, trata-se de um fenómeno através do qual crianças leem literatura própria para adultos ["Literature written with adults as the intended audience but which crosses over or is also read by children and young adults" (ANGGRAINI, 2015, p. 8)] ou adultos leem literatura infantil ["Literature written for children or young adults that is also read by adults." (ANGGRAINI, 2015, p. 9)].
} 
se adapta às idiossincrasias do público-alvo, que intenção moralizadora é veiculada e até que ponto a moralidade varia consoante a época de elaboração do texto.

A fábula escolhida - do leão e do rato - narra a história de um leão que é incomodado por um rato enquanto dorme. Apanhando-o, o leão liberta-o depois de o rato o convencer que um dia lhe poderá ser útil. Tal vem a suceder quando o leão é apanhado numa armadilha: o rato rói as cordas e solta-o.

Ainda que existam variações dentro do corpus, como no número de ratos, ${ }^{22}$ no seu género - em Tavares (1929) uma rata ensinava os filhos a saltar - ou pela amplificação da narrativa - Mantegazza (1997) insere um corvo na história, Oom (2005b) integra duas canções, Fonseca (2000) narra uma festa de ratos -, a maioria das obras é fiel à versão esopiana.

O mesmo não se pode dizer do epimítio, que nem sempre é apresentado, sendo inferido pelo leitor em vários casos:

- Fonseca (2000): preso, o leão reconhece que o rato pode ser uma "preciosa ajuda" e que foi errado rir-se dele, pedindolhe perdão;

- Oom (2005a): a última fala do texto remete para a moralidade; ${ }^{23}$

- Waters (2011): para além do epimítio declarado, ${ }^{24}$ a última fala do rato introduz a moral: "Por vezes, até os poderosos precisam da ajuda dos mais pequenos." (WATERS, 2011, p. 6)

Em outros casos, a moralidade é tão ténue que aproxima a narrativa mais de um conto de animais que de uma fábula:

- Mantegazza (1997, p. 5): “O leão olhou para ele com um ar surpreendido ao ver salva a sua vida por um ratinho agradecido!",25

\footnotetext{
${ }^{22}$ Cf. MACHADO, 1957; VIDIGUEIRA, 1643.

23 "Muito bem, vou ajudar-te, mas para a próxima vez lembra-te de que não te deves achar mais importante do que os outros, só porque és grande e poderoso!" (OOM, 2005a, p. 26).

24 "Nunca substimes (sic) os outros pela sua aparência." (WATERS, 2011, p. 6).

${ }^{25}$ Infere-se, porque o rato está agradecido, que devemos sentir gratidão por um favor que nos fazem.
} 
- Tavares (1929, p. 99): “Aí tem, senhor leão, a paga da sua generosidade de há tempos. Lembra-se? Não se lembra, por certo; mas eu é que não me esqueci. Estamos pagos!".

Fora essa discrepância, em geral, praticamente todas as narrativas analisadas transmitem uma moralidade, ainda que esta varie.

Segundo Pereira, essa fábula veicula a seguinte moralidade:

O leão [...] representa a força e o poder absolutos [...]. $O$ Leão e o Rato e $O$ Leão e o Mosquito incentivam os monarcas absolutos a respeitar os mais fracos e os súbditos de que realmente dependem. Por muito humildes que sejamos podemos sempre possuir algo que interesse ou que incomode os mais fortes. [...] A lição é optimista e leva a uma coesão social considerável, sem falar do alívio dos medos e das tensões que prodiga aos deserdados e desprotegidos, funcionando para os mais novos como um reforço para a construção da sua identidade e para o reforço dos mecanismos de valorização das competências necessárias a um percurso de crescimento pejado de obstáculos, aparentemente inultrapassáveis. (PEREIRA, 2003, p. 196-197) 26 .

Assim sendo, a moralidade, no geral, parece ligar-se ao dever de respeito pelos mais fracos, à consciência de que os humildes têm um papel a desempenhar e à necessidade de cada um tomar consciência do seu valor.

Contudo, há outras possibilidades de leitura nos textos estudados (vide anexo):

${ }^{26}$ Cf. PEREIRA, 2003, p. 264-268. 


\begin{tabular}{|c|c|}
\hline Leitura & Obras \\
\hline $\begin{array}{l}\text { a. Os poderosos não devem desprezar } \\
\text { nem subestimar os humildes, pois } \\
\text { dependem deles. }\end{array}$ & $\begin{array}{l}\text { LIVRO..., 1994; VIDIGUEIRA, 1643; MOTA, } \\
\text { 2004; GUERREIRO, 1788; FREDERICO, } \\
\text { 1930; BRAGANÇA, 1984; AS MAIS..., 1994; } \\
\text { FONSECA, 2000; OOM, 2005a; OOM, 2005b; } \\
\text { WATERS, 2011; SARABANDO, } 2015 .\end{array}$ \\
\hline $\begin{array}{l}\text { b. Não se deve ofender os pequenos } \\
\text { ou humildes. }\end{array}$ & PEREIRA, 1871 \\
\hline $\begin{array}{l}\text { c. Devemos mostrar gratidão pelo } \\
\text { bem que nos fazem. }\end{array}$ & $\begin{array}{l}\text { VIDIGUEIRA, } 1643 \text {; GUERREIRO, } \\
\text { 1788; FREDERICO, 1930; OOM, 2005b; } \\
\text { MANTEGAZZA, } 1997 \text {. }\end{array}$ \\
\hline $\begin{array}{l}\text { d. Fazer o bem e ajudar os outros é } \\
\text { bom, sejamos grandes ou pequenos. }\end{array}$ & $\begin{array}{l}\text { O’NEILL, } 1885 ; \text { MACHADO, } 1957 \text {; } \\
\text { KINCAID, } 1997 .\end{array}$ \\
\hline $\begin{array}{l}\text { e. Todas as funções são importantes, } \\
\text { mesmo as que, aparentemente, são } \\
\text { insignificantes, e cada um deve saber } \\
\text { o seu valor. }\end{array}$ & $\begin{array}{l}\text { OOM, 2005b; RANGEL, 2008; SARABANDO, } \\
2015 .\end{array}$ \\
\hline $\begin{array}{l}\text { f. Devemos estar alertas para o que } \\
\text { nos sucede, mesmo que nos sintamos } \\
\text { fortes. }\end{array}$ & PARREIRA, 2005. \\
\hline
\end{tabular}

Nota-se, por esta breve análise, que todas as ideias veiculadas por Pereira na descrição que faz do valor ético dessa fábula estão representadas nas moralidades declaradas/inferidas em cada narrativa, sendo possível acrescentar outras ideias: a importância da gratidão, a recusa da ofensa aos humildes, o valor de fazer o bem, a humildade que deve ser cultivada. Estamos assim perante uma fábula cuja riqueza moral subjacente é evidente.

A esse nível, importa destacar ainda:

- há valores sociais que mantêm a sua importância independentemente do momento cultural ou século que se atravessa: os poderosos não devem desprezar ou subestimar os humildes e deve-se demonstrar gratidão; 
- cada um deve ter consciência do seu valor e da importância do trabalho de todos. Essa ideia é veiculada apenas em obras atuais, indo ao encontro das ideias relacionadas com a igualdade e a necessidade de autoconfiança atualmente defendidas.

Por fim, os epimítios permitem-nos verificar a existência de uma evolução na forma como a moralidade é apresentada. Note-se que até o século XX há uma tendência para explorar de forma profunda o valor moral da fábula e que, quando esta passa a integrar a literatura para a infância, a linguagem se simplifica, diminuindo a necessidade de profusas explicações. ${ }^{27}$ Assim sendo, é claro que na maioria dos epimítios se tem em conta o público-alvo definido. De facto, até ao século $\mathrm{XX}$, e excetuando o promítio de Pereira, os fabulários analisados são sentenciosos e procuram explorar pedagogicamente a narrativa, notandose uma preocupação em instruir o público adulto a que se destinam. $\mathrm{O}$ mesmo não acontece com os fabulários mais recentes dirigidos a adultos ou jovens, ${ }^{28}$ que seguem a tendência de simplificação da moralidade que se verifica também a partir de O’Neill, isto é, desde que a fábula começa a dirigir-se sobretudo a um público infantojuvenil. ${ }^{29}$

\section{Conclusão}

Nesta investigação, procurámos analisar algumas questões que nos pareceram pertinentes acerca da recepção de Esopo em Portugal.

Nesse âmbito, depois de analisarmos a definição de "fábula" e observarmos como este género foi integrado à literatura para a infância em Portugal, procurámos fazer uma breve resenha dos mais representativos fabulários e obras avulsas ligados a Esopo em Português, observando especificidades das obras, nomeadamente seus paratextos, para retirar conclusões sobre o público-alvo a que se destinavam. Isto permitiu-nos

\footnotetext{
27 " $N a$ evolução deste gênero literário, nota-se a inversão da importância destes dois elementos: quanto mais se avança na história da fábula, mais se vê decrescer o caráter sentencioso e pedagógico em proveito da ação.” (PORTELLA, 1983, p. 123).

${ }^{28}$ MACHADO, 1957; BRAGANÇA, 1984; RANGEL, 2008.

${ }^{29}$ A única exceção é o epimítio de Ducla Soares (OOM, 2005b) que surge como um texto independente, separado do texto principal (contrariamente à narrativa, em que as páginas são profusamente ilustradas, a moral da história é apresentada em páginas em branco, provocando um corte visual com a fábula narrada).
} 
concluir que as fábulas esopianas estão escritas preferencialmente em prosa e seguem a tendência geral de abandonar o público-alvo adulto e se integrar à literatura para a infância, onde ainda hoje permanecem.

Para além disso, foi ainda possível registar, a partir da análise breve de uma fábula, que existem diversas possibilidades de leitura no que toca à moralidade e que, se algumas são intemporais, outras relacionam-se concretamente com temáticas atuais. Note-se, contudo, que a apresentação desses valores se alterou: até ao século XX há tendência para explorar profundamente os epimítios, dando atenção à instrução moral dos adultos; quando a criança passa a ser a principal destinatária dos textos, simplifica-se a mensagem, chegando a verificar-se até a ausência declarada de moralidade, o que aproxima a fábula dos contos sobre animais.

Por fim, concluímos que as fábulas esopianas, cuja primeira aparição em português se regista na Idade Média, mantêm a sua vitalidade no mercado editorial português, tendo predominantemente como alvo o público infantojuvenil, a que se junta, concomitantemente, uma tendência para valorizar a ilustração. Contudo, tal não impede que continuem a surgir obras que têm como público-alvo os adultos, o que demonstra as possibilidades de leitura de um género que hoje é associado sobretudo à literatura para a infância.

\section{Referências}

\section{Corpus analisado}

AS MAIS belas fábulas de Esopo. Ilustração de M. Fiodorov. [S.1]: Civilização, 1994.

BRAGANÇA, M. G. Fábulas: as cem mais famosas fábulas de Esopo. Lisboa: Europa-América, 1984.

FONSECA, F. O leão e o rato: e, Capuchinho vermelho. [S.1.]: MTS Editores, 2000.

FREDERICO, C. Contos para crianças - fábulas de Esopo. Porto: Lello, 1930.

GUERREIRO, M. C. Fabulas de Esopo. Lisboa: Francisco Luiz Ameno, 1788. 
KINCAID, L. Fábulas de Esopo. Porto: Asa, 1997.

LIVRO de Exopo. Edição crítica de A. A. Calado. Coimbra: Univ. Coimbra, 1994.

MACHADO, A. Fábulas de animais e outras - Esopo / La Fontaine. Lisboa: Portugália, 1957.

MANTEGAZZA, G. O leão e o ratinho. [S.1.]: Campo das Letras, 1997.

MOTA, A. Fábulas de Esopo. Alfragide: Asa, 2004.

O’NEILL, H. Fabulário. Lisboa: Livraria Ferreira, 1885.

OOM, A. (Adapt.). O rato e o leão. Lisboa: Zero a Oito, 2005a.

OOM, A. O leão e o rato. Lisboa: Zero a Oito, 2005 b.

PARREIRA, F. Fabuloso Esopo. Setúbal: Marina Editores, 2005.

PEREIRA, J. F. 113 fabulas de Esopo. Lisboa: Lucas Evangelista Torres, 1890.

PEREIRA, J. F. Fabulas de Phedro. Lisboa: Typ., Rua da Vinha, 1871.

RANGEL, A. Fábulas de Esopo para executivos. Cruz Quebrada: Casa das Letras, 2008.

SARABANDO, M. J. (Adapt.). Fábulas para aprender. Porto: Porto Editora, 2015.

TAVARES, J. P. Cinquenta fabulas de Fedro. Aveiro: Livraria Carlos Alberto, 1929.

VIDIGUEIRA, M. M. Vida e fábulas do insigne fabulador grego Esopo. Lisboa: Antonio Alvarez, 1643.

WATERS, F. As fábulas de Esopo. Porto: Civilização, 2011.

\section{Estudos}

ANGGRAINI, T. E. The Characteristics of Child-to-Adult Crossover Literature. Ohio: OSU, 2015.

ARAÚJO, M. R. Cachorros do céu: as transformações da fábula em Wilson Bueno. São Paulo: Unesp, 2012. 
BARRETO, A. G. Dicionário de literatura infantil portuguesa. Porto: Campo das Letras, 2002.

BECKETT, S. L. Crossover Fiction: Global and Historical Perspectives. New York: Routledge, 2009.

BLOCH, M. A sociedade feudal. Lisboa: Edições Setenta, 1982.

DEZOTTI, M. C. C. A tradição da fábula: de Esopo a La Fontaine. Brasília: Univ. Brasília, 2003.

FERREIRA, J. R. Educação em Esparta e em Atenas. In: LEÃO, D. et al. Paideia e cidadania. Coimbra: Ariadne, 2006.

FERREIRA, N. H. S. Aesopica - a fábula esópica e a tradição fabular grega. Coimbra: Univ. Coimbra, 2014.

GOMES, J. A. Literatura para a infância e a juventude e promoção da leitura. [S.1.]: Ccasa da Leitura: 2007. Disponível em: <http:// magnetesrvk.no-ip.org/casadaleitura/portalbeta/bo/documentos/ot_litinf promleit_a.pdf $>$. Acesso em: 31 mar. 2017.

KURKE L. Aesopic Conversations: Popular Traditions, Cultural Dialogue, and the Invention of Greek Prose. Princeton: Princeton University Press, 2011.

LEM-OS, E. A literatura infantil em Portugal. Lisboa: MEN-DGEP, 1972.

LERER, Seth. Children's Literature: A Reader's History, from Aesop to Harry Potter. Chicago: UCP, 2009.

MARROU, H. I. Histoire de l'éducation dans l'Antiquité. Paris: Seuil, 1948.

MORAIS, A. P. História crítica da fábula na literatura portuguesa. [S.1,: S.n.\}, [2008?]. cap. 3: A coleção de fábulas traduzidas por Manuel Mendes da Vidigueira, 1603-1914. Disponível em: < http://www.memoriamedia. net/bd docs/Fabula/3.\%20A\%20colecao $\% 20 \mathrm{de} \% 20$ fabulas $\% 20 \mathrm{de} \% 20$ Manue $1 \% 20$ mendes $\% 20 \mathrm{da} \% 20$ Vidigueira_Ana $\% 20$ Morais.pdf $>$. Acesso em: 31 mar. 2017.

NEVES, M. H. M. A gramática pela fábula. Lingüística, Asociación de Lingüística y Filología de América Latina, v. 30, n.1, p. 165-196, 2014.

PATRIARCA, R. O livro infantojuvenil em Portugal entre 1870 e 1940. Porto: FLUP, 2012. 
PAUL, J. Histoire intellectuelle de l'occident médiéval. Paris: Colin, 1973.

PEREIRA, L. A fábula em Portugal. Lisboa: UNL, 2003.

PEREIRA, M. H. R. Estudos de história da cultura clássica. Lisboa: FCG, 1987.

PLATÃO. A república. Tradução de Edson Bini. São Paulo: Edipro, 2012.

PORTELLA, O. O. A fábula. Revista de Letras, Curitiba, v. 32, p. 119138, 1983.

RAMOS, A. M. As fábulas e os bestiários na literatura de recepção infantil contemporânea. Forma Breve, Aveiro, n. 3, p. 169-194, 2005.

REIS, C.; LOPES, A. C. M. Dicionário de narratologia. Coimbra: Almedina, 1994.

ROCHA, N. Breve história da literatura para crianças em Portugal. Lisboa: Caminho, 2001.

RODRÍGUEZ ADRADOS, F. De Esopo al Lazarillo. Huelva: Univ. Huelva, 2005.

RODRÍGUEZ ADRADOS, F. Historia de la fábula greco-latina. Madrid: Univ. Complutense, 1979. v. 1.

ROSADO, I. Literatura para a infância-concepções e acompanhamento parental. Coimbra: ESE, 2011.

ROTHWELL, K. S. Aristophanes' Wasps and the Socio-politics of Aesop's fables, The Classical Journal, CAMWS, v. 93, n. 4, p. 233-254, 1995.

SCHON, I.; BERKIN, S. C. Introducción a la literatura infantil y juvenil. Newark: International Reading Association, 1996.

SILVA, V. M. A. Nótula sobre o conceito de literatura infantil. In: SÁ, D. G. A literatura infantil em Portugal. Braga: Editorial Franciscana, 1981. p. 9-15.

TARRÍO VARELA, A. et alii. Diccionario de termos literarios. Santiago de Compostela: Centro Ramón Piñeiro, 1998. 


\section{Anexo}

- Livro de Exopo (1994, fábula 46): "Em esta hestoria o doutor emssina os gramdes homẽes do mundo e os poderosos que nom despreçem os pequenos que ham pequeno poder, ca nom he nhũu homem de tam pequeno poder que nom possa seer proveytoso em algũu tempo aaquell que he gramde e poderoso. Tall serviço lhe pode fazer hũu homem pequeno que lho nom pode fazer hũu gramde."

- Vidigueira (1643, f. 47v): "Duas cousas temos aqui que notar primeiramente, o agradecimento, que se deve a qualquer boa obra, e em especial a quem perdoa algũ agravo, podẽndo vingarse, como este Leão podia. Segundariamente quando devẽ os poderosos estimar a amisade de qualquer homẽ por muito fraco q seja, porque qualquer pode fazer mal, e senão podẽ fazer mal, todos podẽ fazer bẽ."

- Guerreiro (1788, p. 243): "Tendo todo o direito hum desvalido/De que delle em miserias te condoas/Por hum erro geral mais te affeiçoas/A quem he de infinitos soccorrido./O bem he muito mais agradecido/Por pessoas rasteiras, se são boas;/Que se muito se faz a outras pessoas/ Cuidaõ que muito mais lhes he devido./Dirás: Se elle não tem o que lhe baste,/Onde hade ir buscar premio, que accomode/A quem em seu favor trabalhe ou gaste?/Lá vem hum grande mal em que te acode,/ Podendo, como nunca imaginaste;/E demos que naõ possa, em quem pode."

- Pereira (1871, p. 78): "Esta fábula admoesta, que ninguem offenda os mais pequenos."

- O’Neill (1885, p. 519): “Sempre é bom fazer o bem/ Inda a qualquer João-Ninguém."

- Frederico (1930, p. 39): "Nunca se deve desprezar, mesmo quando se é poderoso, a amizade dos humildes que, se não podem fazer mal em certos casos, poderão sempre fazer bem. E não se esqueça ainda que todo o favor recebido merece a gratidão de quem o recebe."

- Machado (1957, p. 44): “[...] grandes ou pequenos, todos nós podemos ser bons e úteis."

- Bragança (1984, p. 29): "Não há no mundo nenhum ser tão grande e tão importante que nunca venha a precisar do auxílio dum pequeno e insignificante."

- As mais belas fábulas de Esopo (1994, p. 12): "Esta fábula convidanos a não desprezar os mais fracos que, frequentemente, possuem inesperados recursos." 
- Kincaid (1997, p. 17): "Por vezes podemos ajudar outros muito maiores do que nós."

- Mota (2004, p. 35): "Nunca desprezes as promessas e o trabalho dos mais pequenos."

- Parreira (2005, p. 31): "Faz como o leão: não te julgues tão esperto e tão forte a ponto de não precisares de estar sempre alerta perante as coisas mais pequenas."

- Oom (2005b, p. 26-27): "Haverá alguém que nunca necessite dos outros? A sociedade é formada por um conjunto de seres interdependentes e todos os elos dessa cadeia têm a sua especificidade, a sua importância. Mesmo os mais fortes, os mais poderosos, os mais valentes, que se consideram, como o leão, reis e senhores, um dia hão-de reconhecer que é bem preciosa a ajuda dos fracos, dos ratinhos aparentemente insignificantes. Mal de quem despreza os humildes, pensando, no seu orgulho, que são criaturas sem préstimo nem valor. Quando chegar um momento de aflição, como poderão contar com a sua indispensável assistência? Muitos meninos (e não só), se sentem, como o rato da fábula, bem pequenos e frágeis diante dos grandes que podem e mandam. Como é que hão-de enfrentá-los? Tremendo de medo? Fugindo a sete pés? Entregando-se ao desespero e ficando paralisados? Por que não, seguindo o exemplo do herói da fábula, tendo a coragem de falar, recordando que também têm o seu préstimo? Há tantas coisas que a gente miúda faz com desembaraço e que certos matulões são incapazes de realizar [...] Ser pequeno não significa ser inferior porque os "homens não se medem aos palmos"' (SOARES apud OOM, 2005b p. 26-27). "E assim à gente ensinando/De ser grato a obrigação,/Também mostra aos insofridos/Que o trabalho com paciência/Faz mais que a força, a imprudência/Dos que em fúria sempre estão." (SEMEDO apud OOM, 2005b, p. 29)

- Rangel (2008, p. 114): "Numa empresa, todas as funções têm o seu valor, por mais simples que possam parecer."

- Sarabando (2015, p. 84): "Nunca subestimes os mais fracos. Lembra-te de que a verdadeira força não está nos músculos, mas na inteligência e na competência e, sobretudo, na audácia e na coragem com que enfrentamos os problemas." 